\title{
Elicitation of Trigonelline and 4-Hydroxyisoleucine with Hypoglycemic Activity in Cell Suspension Cultures of Trigonella foenum graecum L.
}

\author{
Ahmed M.A. Abd-El Mawla*,a,b and Husam Eldien H. Osman ${ }^{\mathrm{c}}$ \\ ${ }^{a}$ Department of Pharmacognosy, Faculty of Pharmacy, Assiut University, Assiut 71526, Egypt \\ ${ }^{b}$ Department of Pharmacognosy, Faculty of Pharmacy, Taif University, Taif 21974, Saudi Arabia \\ ${ }^{c}$ Department of Anatomy and Histology, Faculty of Medicine and Medical Sciences, Taif University, Taif 21974, Saudi \\ Arabia
}

\begin{abstract}
Cell suspension cultures of Trigonella foenum graecum L. (fenugreek) were initiated from the cotyledon portions of sterile germinated seeds and maintained on MS medium supplemented with 2, 4-dichlorophenoxy acetic acid $(2,4-\mathrm{D})(1 \mathrm{mg} / \mathrm{l})$, kinetin $(0.1 \mathrm{mg} / \mathrm{l})$ and sucrose $(5 \%)$. The changes in cell mass and both trigonelline and 4hydroxyisoleucine content were followed between days zero and 12. The linear increase in fresh weight was found to be parallel to both trigonelline and 4-hydroxyisoleucine production. Cell suspension cultures treated with $100 \mu \mathrm{M}$ methyl jasmonate (MJ) for 24 hours showed a noticeable increase in the level of trigonelline and 4-hydroxyisoleucine. The marked improvement in the histological and electron microscopically pictures of pancreas of STZ-diabetic rats fed with extract of cells treated with MJ is coincided with more effective and significant hypoglycemic activity than that for seeds extract. The extract of cultured cells treated with MJ lowered blood glucose from $284 \pm 7.4$ to $123 \pm 8.1$ units and increased the insulin level from $4.42 \pm 0.23 \mu \mathrm{U} / \mathrm{ml}$ to a high level $8.33 \pm 0.41 \mu \mathrm{U} / \mathrm{ml}$.
\end{abstract}

Keywords: Trigonella foenum graecum, MS medium, trigonelline, 4-hydroxyisoleucine, methyl jasmonate, HPLC.

\section{INTRODUCTION}

Fenugreek (Trigonella foenum-graecum L. Leguminosae) is one of the oldest medicinal plants. This plant is thought to originate from India or the Middle East. It is now primarily grown in India and in the Mediterranean countries.

It is an annual herbaceous plant belonging to the Fabaceae family, $40-60 \mathrm{~cm}$ high, with alternate trifoliate leaves and pale yellow flowers. The leaves and seeds, which mature in long pods, are used to prepare extracts or powders for medicinal use.

In ancient Egypt, fenugreek was used in incense and to embalm mummies. In modern Egypt, fenugreek is still used as a supplement in wheat and maize flour for bread-making [1]. In ancient Rome, fenugreek was purportedly used to aid labor and delivery. In traditional Chinese medicine, fenugreek seeds are used as a tonic, as well as a treatment for weakness and edema of the legs [2]. In India, fenugreek is commonly consumed as a condiment [2] and used medicinally as a lactation stimulant [3]. It is widely considered as an antidiabetic and anticholesterol herb. Various clinical trials of fenugreek showed improvement in glucose tolerance in healthy volunteers as well as in type 2 and type 1 diabetic patients [4-7].

Trigonelline is known to have some hypoglycemic effect. The effect of an alkaloid extract of fenugreek dried seeds (Trigonella foenum graecum L.) on blood glucose, serum

*Address correspondence to this author at the Department of Pharmacognosy, Faculty of Pharmacy, Assiut University, Assiut 71526, Egypt; Tel: +20882411330; Fax: +20882332776;

E-mail: Ahmedpha2000@yahoo.com insulin, serum lipid profile and lipid peroxidation in addition to histological and histochemical study of liver and kidney in streptozotocin induced diabetic albino rats have been studied [8]. Further investigations concerning the protective effect of Trigonella foenum graecum $\mathrm{L}$. on the histological structures and function of liver, kidney and pancreas of induced diabetes were studied [9-12].

However, most attention has been given to 4hydroxyisoleucine. From the seeds of $T$. foenum-graecum an unusual amino acid, 4-hydroxyisoleucine, has been isolated, which significantly decreased the plasma triglyceride levels by $33 \%(\mathrm{P}<0.002)$, total cholesterol $(\mathrm{TC})$ by $22 \%(\mathrm{P}<0.02)$, and free fatty acids by $14 \%$, accompanied by an increase in HDL-C/TC ratio by $39 \%$ in the dyslipidemic hamster model [13]. In vitro, it was shown to increase glucose-induced insulin release in human and rat pancreatic islet cells [14, $15]$.

Plant tissue culture technique is being used for producing primary and secondary metabolites as early as 1950's. Since then this technique has been developed for the production of various secondary metabolites [16-19]. As a part of our continuing interest concerning the production of biologically active compounds by tissue culture [20-22], the present work describes optimum conditions to induce accumulation of hypoglycemic trigonelline and 4-hydroxyisoleucine in cell suspension cultures of Trigonella foenum graecum $\mathrm{L}$.

\section{MATERIALS AND METHODS}

\section{General Procedures}

TLC was performed on silica gel $60 \mathrm{~F}_{254}$-coated aluminum sheets (Merck, Darmstadt, Germany). Plates were visualized by spraying with Dragendorff reagent. 
EI-MS analysis was carried out on a JEOL JMS 600 mass spectrometer (Japan).

HPLC analysis was carried using an L-6200A intelligent pump and L-4000 UV detector (Merck, Germany).

The insulin- EASIA was performed using an Anthos Labtec Instrument; 400-700 nm wavelength (Austria) and Anthos Fluido 2 Microplate Washer, Biochrome Ltd, Cambridge, UK.

\section{Chemicals and Kits}

Trigonelline hydrochloride, 4- hydroxyisoleucine, methyl jasmonate and streptozotocin were purchased from SigmaAldrich, Germany. Glucose (GO) assay kit was purchased from Sigma-Aldrich (Germany). GenWay Insulin-ELISA kit was purchased from GenWay Biotech, San Diego, USA.

All the media components were purchased from E-Merck (Darmstadt, Germany).

\section{Plant Material}

The seeds of Trigonella foenum-graecum were obtained from Pharmacognosy Department, College of Pharmacy, Taif University, Taif, Saudi Arabia.

\section{Cell Suspension Cultures}

Seeds of Trigonella foenum-graecum were rinsed in water, and then sterilized with $70 \%$ ethanol for few seconds, immersed in $0.1 \%$ mercuric chloride solution for 15 minutes and washed three times with sterile distilled water. The sterilized seeds were germinated on $50 \mathrm{ml}$ solid MS medium [23], containing $2.0 \mathrm{mg} / \mathrm{l} 1$-naphthyl acetic acid (NAA), 0.2 $\mathrm{mg} / \mathrm{l} \mathrm{6-(furfurylamino)-purine} \mathrm{(kinetin),} 4 \mathrm{~g} / \mathrm{l}$ phyta-gel and $30 \mathrm{~g} / \mathrm{l}$ sucrose at $\mathrm{pH} 5.75$ and $25 \pm 2{ }^{\circ} \mathrm{C}$ in the dark. The resulting cotyledon portions were cultivated on MS medium supplemented with 2, 4-dichlorophenoxy acetic acid (2, 4-D) $(1 \mathrm{mg} / \mathrm{l})$, kinetin $(0.1 \mathrm{mg} / \mathrm{l})$ and sucrose $(5 \%)$ at $\mathrm{pH} 5.75$ and $25 \pm 2{ }^{\circ} \mathrm{C}$ in the dark. The resulting callus tissues were subcultured at 3-week intervals. Cell suspension cultures were established by transferring callus tissues in $50 \mathrm{ml}$ liquid MS medium (without phyta gel) with the same hormones supplementation. Cultures were shaken in 300-ml Erlenmeyer flasks at 100 r.p.m. and $25 \pm 2{ }^{\circ} \mathrm{C}$ in the dark. Cell suspension cultures were subcultured every 7-10 days at the end of exponential growth phase.

\section{Growth Curve}

Ten flasks with fresh liquid MS medium $(50 \mathrm{ml})$ were prepared and inoculated with $4 \mathrm{~g}$ cultured cells of Trigonella foenum-graecum (day zero). Fresh weight (FW) and trigonelline and 4- hydroxyisoleucine content were determined from day zero to day 12 at two days interval.

\section{Effect of Methyl Jasmonate}

$4 \mathrm{gm}$ (FW) of cultured cells of Trigonella foenumgraecum were inoculated in $50 \mathrm{ml}$ MS medium. Cultured cells of Trigonella foenum-graecum in exponential phase (4 days-old cultures) were exposed to $100 \mu \mathrm{M}$ methyl jasmonate (MJ) for $24 \mathrm{~h}$. Cultured cells were harvested by vacuum filtration, weighed and kept at $-20{ }^{\circ} \mathrm{C}$ for the extraction procedure and HPLC analysis. Growth (FW) and Trigonelline and 4-hydroxyisoleucine accumulation in the cultured cells were determined.

\section{Extraction of Trigonelline and 4-Hydroxyisoleucine}

$100 \mathrm{~g}$ of both the Trigonella foenum-graecum seeds and cultured cells (control \& treated) were separately homogenized in $10 \mathrm{M} \mathrm{HCl}$, filtered, and the acid aqueous solution was then stirred with zinc dust overnight, filtered and extracted with $\mathrm{CH}_{2} \mathrm{Cl}_{2}$ to yield the total alkaloids [24].

The $\mathrm{CH}_{2} \mathrm{Cl}_{2}$ extract was evaporated till dryness. The residues were re-dissolved in $10 \mathrm{ml}$ acidulated methanol for phytochemical study and HPLC analysis.

\section{Isolation and Identification of Trigonelline and 4-} Hydroxyisoleucine

A preliminary phytochemical analysis was carried out using thin-layer chromatography (TLC) for detecting the presence of trigonelline and 4-hydroxyisoleucine [25]. The two major spots related to Trigonelline and 4hydroxyisoleucine (Fig. 1) were separated by preparative TLC using $\mathrm{CH}_{2} \mathrm{Cl}_{2}-\mathrm{MeOH}-25 \% \mathrm{NH}_{4} \mathrm{OH}(85: 15: 2 \mathrm{v} / \mathrm{v})$ as a solving system. Their EI-MS spectra agreed with published data $[14,15]$.

Furthermore, co-chromatography (TLC \& HPLC) with reference compounds was performed.

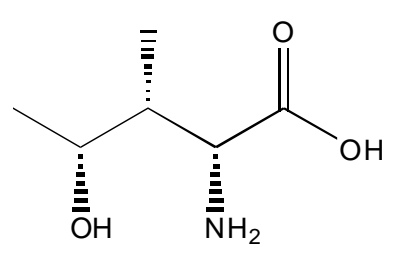

4-Hydroxyisoleucine<smiles>C[n+]1cccc(C(=O)O)c1</smiles>

Trigonelline
Fig. (1). Chemical structure of the isolated compounds.

\section{HPLC Analysis}

The quantities of Trigonelline and 4- hydroxyisoleucine in both the Trigonella foenum-graecum seeds and cultured cells (control \& treated) were determined by HPLC; $30 \mu 1$ was injected and a reversed phase (styrene-divinylbenzene resin) column (150x4.1 mm, PRP-1, $10 \mu \mathrm{m})$ was used. $0.1 \mathrm{M}$ ammonium hydroxide (A) and acetonitrile (B) were used as solvents. The employed gradient was: $10-30 \%$ (B) in $30 \mathrm{~min}$. The flow rate was $1 \mathrm{ml} / \mathrm{min}$ and the detection wavelength set to $265 \mathrm{~nm}$. Trigonelline and 4- hydroxyisoleucine in a concentration of $1 \mu \mathrm{g} / 100 \mu \mathrm{l}$ were used separately as reference compounds. The quantities of both were estimated on the bases of their area with respective to the area of references $(0.3 \mu \mathrm{g})$ as external standards.

\section{Animals and Induction of Diabetes}

Male Wister rats weighing 180-200 g were obtained from the experimental animal care centre, King Abdelaziz University, Jeddah, Saudi Arabia. Induction of diabetes was performed as previously published [26]. The STZ was dissolved in $0.1 \mathrm{ml}$ of citrate buffer ( $\mathrm{pH} 4.5$ ). A single dose of STZ $(60 \mathrm{mg} / \mathrm{kg})$ was injected intraperitoneally in animals for induction of diabetes. 
STZ-treated rats were given $5 \%$ glucose in their drinking water for the first $24 \mathrm{~h}$ to counter any initial hypoglycemia. Normal animals were similarly injected with vehicle only. On the third day, the animals were checked for the presence of glucose in the urine using enzymatic test strips. The animals were maintained under standard conditions of temperature $25 \pm 5 \circ \mathrm{C}$ and $55 \pm 5 \%$ relative humidity with a regular $12 \mathrm{~h}$ light: $12 \mathrm{~h}$ dark cycle and allowed free access to standard laboratory food (Purina Chow) and water. All animals were treated humanely in accordance with the guideline for care of animals as set by WHO.

\section{Biological Study}

As mentioned previously in literature [26]; the rats were randomly divided into four groups of 10 animals each. The first group was received citrate buffer alone (normal), the second was STZ-diabetic rats (control), the third was the STZ-diabetic rats fed orally with $50 \mathrm{mg} / \mathrm{kg} /$ day seeds extract of Trigonella foenum graecum, and while the fourth was the STZ-diabetic rats fed orally with $50 \mathrm{mg} / \mathrm{kg} /$ day extract of cultured cells treated with MJ for 10 successive days.

On the eleventh day, the rats were subjected to light ether anesthesia and killed by cervical dislocation. Trunk blood was collected into heparinised chilled tubes containing sodium fluoride (to inhibit glycolysis). Serum was separated by centrifugation at $4{ }^{\circ} \mathrm{C}$ for $15 \mathrm{~min}$ at $3000 \mathrm{rpm}$ and stored at $-20{ }^{\circ} \mathrm{C}$ until determination of serum glucose and serum insulin concentrations.

\section{Haematoxylin and Eosin $(\mathrm{Hx} \& \mathrm{E})$ Staining}

The staining was done to demonstrate the morphologic appearance and the integrity of the specimens. Equal samples from the pancreatic tails $(5 \mathrm{~mm} \times 5 \mathrm{~mm})$ were taken and processed immediately. Paraffin sections were cut at 6um, prepared and stained with Ehrlich hematoxyline and eosin [27].

\section{Ultrastructural Technique}

Adjacent sections of pancreas were removed and placed in $0.1 \mathrm{M}$ cacodylate buffer containing $3 \%$ glutaraldehyde for electron microscopy. After fixation, sections were dehydrated in a series of ethanol rinses, cleared with propylene oxide, and embedded in epon. Ultrathin sections (70-80 nm) were cut using a diamond knife and double stained with uranyl acetate and lead citrate and examined under a transmission electron microscope [27].

\section{Biochemical Analysis}

Serum blood glucose levels were estimated by glucose oxidase method [28]. Serum insulin levels were determined by GenWay INS-EASIA [29].

\section{Statistical Analysis}

Data are expressed as means \pm S.E.M. Statistical comparison between different groups were done using oneway analysis of variance (ANOVA) followed by the TukeyKramer multiple comparison test, to judge the difference between various groups. Significance was accepted at $P<$ 0.05 .

\section{RESULTS AND DISCUSSION}

\section{Trigonelline and 4-Hydroxyisoleucine Accumulation and Growth Curve}

A linear increase in fresh weight was observed between day 2 and day 8 after inoculation of cells into fresh MS medium. HPLC analysis of trigonelline and 4hydroxyisoleucine of untreated cell suspension cultures of Trigonella foenum graecum marked a linear increase in their content between day 4 and day 8 paralleled cell growth (Figs. 2 and 3).

\section{Effect of MJ on Trigonelline and 4-Hydroxyisoleucine Content}

The composition of fenugreek seeds was extensively studied and their composition reveals a few specific features $[14,15,30]$ (Table 1).

$\mathrm{MJ}$ is a substance used in plant defence and many diverse developmental pathways such as seed germination, root growth, flowering, fruit ripening and senescence. In addition,

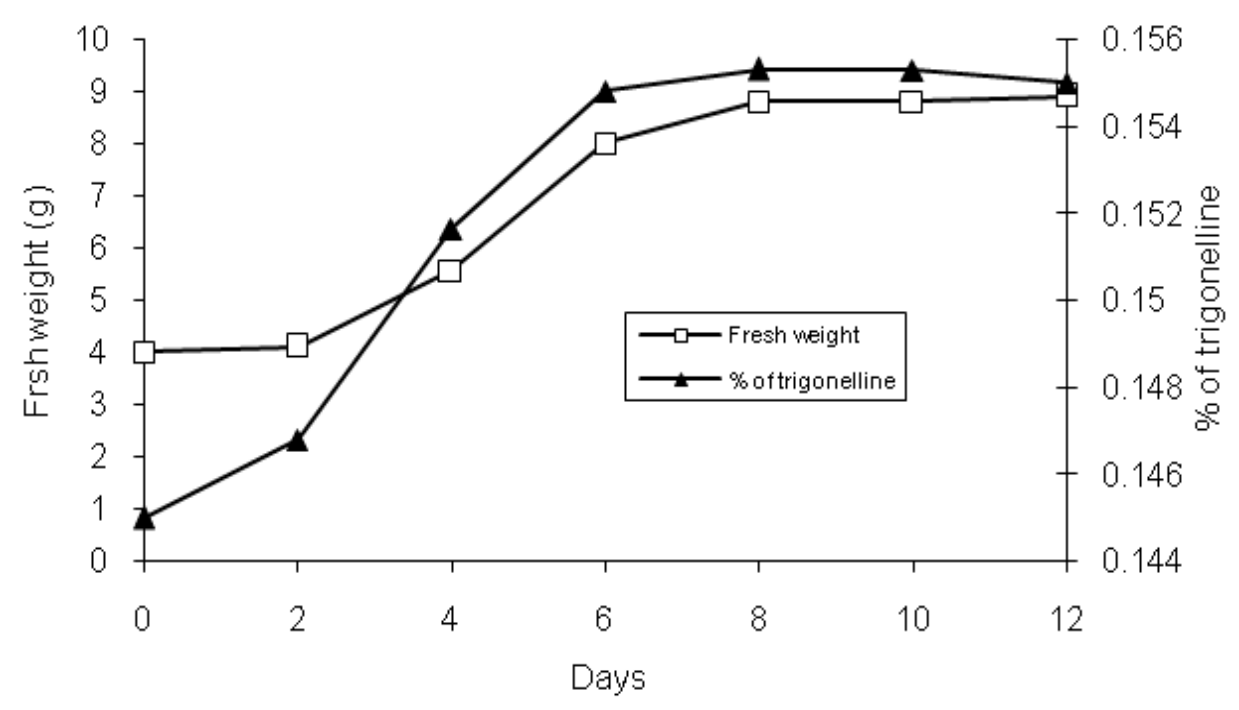

Fig. (2). Changes in fresh weight and trigonelline content of Trigonella foenum graecum cell cultures. The data are mean values of two independent expriments. 


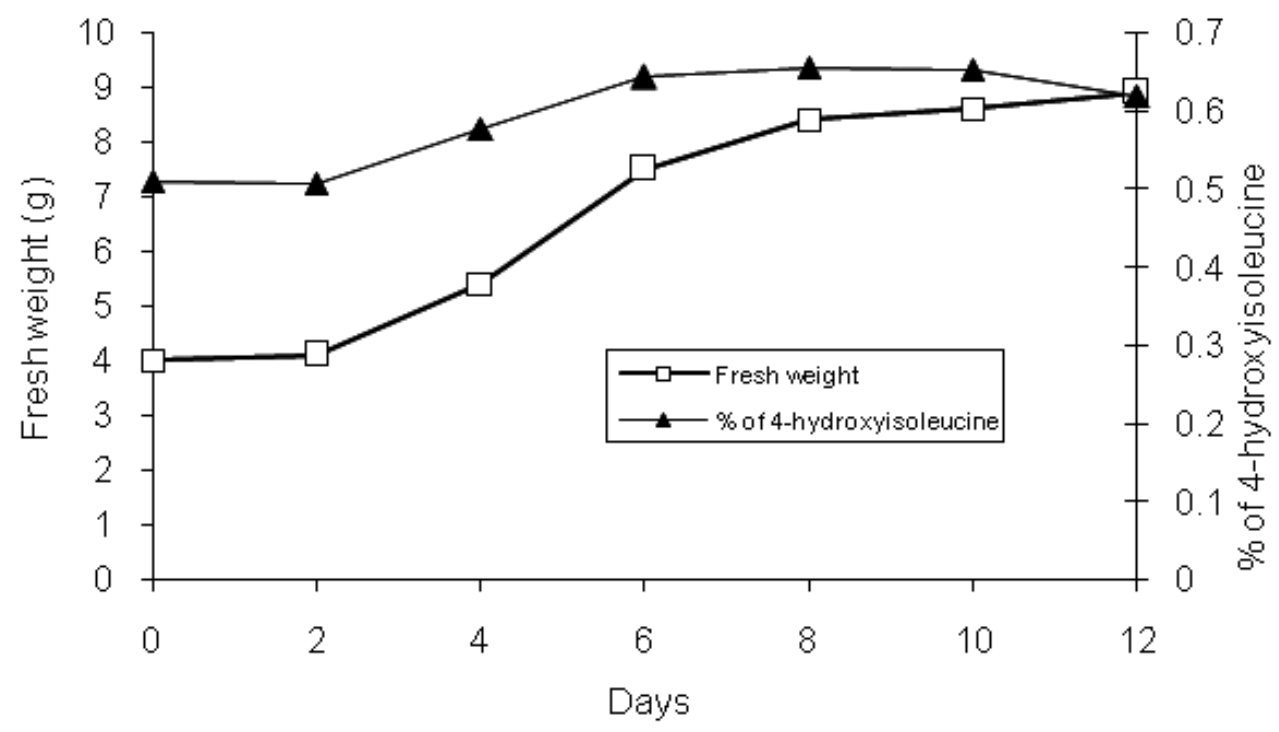

Fig. (3). Changes in fresh weight and 4-hydroxyisoleucine content of Trigonella foenum graecum cell cultures. The data are mean values of two independent experiments.

$\mathrm{MJ}$ is involved in signal transduction and induces the transcription of biosynthetic enzymes involved in the formation of defence compounds in plants [31, 32]. Since MJ can induce the formation of secondary metabolites in other systems [21, 32-34], we have tried to stimulate the accumulation of trigonelline and 4-hydroxyisoleucine in cell suspension cultures of Trigonella foenum-graecum by adding $\mathrm{MJ}$.

The cell suspension cultures of Trigonella foenumgraecum (4 days old) were treated with $100 \mu \mathrm{M}$ methyl jasmonate (MJ) and incubated for $24 \mathrm{~h}$.

The trigonelline and 4-hydroxyisoleucine were extracted and determined quantitatively by HPLC and their estimation was done by peak area calculations. MJ at a concentration of $100 \mu \mathrm{M}$ induced the accumulation of Trigonelline about 2fold and 4-hydroxyisoleucine about 3-fold as compared to the seeds extract (Table 1).

\section{Antidiabetic Activity}

STZ-diabetic rats fed with seeds extract showed lowered blood glucose from $284 \pm 7.4$ to $144 \pm 7.81$ and an increase in the insulin level from $4.42 \pm 0.23 \mu \mathrm{U} / \mathrm{ml}$ to a high level $6.9 \pm 0.47 \mu \mathrm{U} / \mathrm{ml}$. STZ-diabetic rats fed with extract of cells treated with MJ showed lowered blood glucose from $284 \pm$ 7.4 to $123 \pm 8.1$ and an increase in the insulin level from $4.42 \pm 0.23 \mu \mathrm{U} / \mathrm{ml}$ to a high level $8.33 \pm 0.41 \mu \mathrm{U} / \mathrm{ml}$ (Table 2).

The considerable increase in level of both trigonelline and 4-hydroxyisoleucine in the cultured cells treated with MJ as mentioned above (Table 1) compared to the level in the seeds extract is coincided with more effective and significant hypoglycemic activity of extract of the cells treated with MJ. Furthermore, the results of this study agree with published data $[8,13,14]$ which reported the hypoglycemic effect of both trigonelline and 4-hydroxyisoleucine. Trigonelline is known to have some hypoglycemic effect. However, most attention was given to 4-hydroxyisoleucine [15].4Hydroxyisoleucine has been shown to increase glucoseinduced insulin release without interacting with other agonists of insulin secretion such as tolbutamide and glyceraldehydes, thus demonstrating a novel in vitro insulinotropic activity [14].

\section{Histological Picture}

All pancreatic cells of the normal rats were present in their normal proportions. The acinar cells which stained strongly are arranged in lobules with prominent nuclei.

Table 1. Trigonelline and 4-Hydroxyisoleucine Concentrations in Seeds and Cell Suspension Cultures Extracts of Trigonella foenum-graecum

\begin{tabular}{|c|c|c|c|c|}
\hline \multirow[t]{3}{*}{ Extract } & \multicolumn{4}{|c|}{$\%$ of trigonelline and 4-hydroxyisoleucine / seed weight } \\
\hline & \multicolumn{2}{|c|}{ Trigonelline } & \multicolumn{2}{|c|}{ 4-Hydroxyisoleucine } \\
\hline & Found ${ }^{*}, \pm$ SD & Reported & Found $*, \pm$ SD & Reported \\
\hline Seeds & $0.13 \pm 0.03$ & $0.1-0.15$ & $0.58 \pm 0.04$ & 0.6 \\
\hline Control (untreated cells) & $0.16 \pm 0.02$ & - & $0.62 \pm 0.03$ & - \\
\hline Cells treated with $100 \mu \mathrm{M} \mathrm{MJ}$ & $0.27 \pm 0.04$ & - & $1.54 \pm 0.02$ & - \\
\hline
\end{tabular}

*The data are mean values of two independent experiments. 
Table 2. Effect of Seeds and Treated Cells Extracts on Serum Glucose (mg/dl) and Serum Insulin Hormone ( $\mu$ U/ml) in STZDiabetic Treated Rats

\begin{tabular}{|c|c|c|}
\hline Groups & Fasting blood glucose $(\mathbf{m g} / \mathbf{d l})$ & Serum insulin $(\mu \mathbf{U} / \mathbf{m l})$ \\
\hline \hline Normal rats & $77 \pm 3.1$ & $10.7 \pm 0.53$ \\
\hline STZ-diabetic rats (control) & $284 \pm 7.4$ & $4.42 \pm 0.23$ \\
\hline STZ-diabetic rats fed with seeds extract & $144 \pm 7.81$ & $6.9 \pm 0.47$ \\
\hline STZ-diabetic rats fed with extract of cells treated with MJ & $123 \pm 8.11$ & $8.33 \pm 0.51$ \\
\hline
\end{tabular}

*Data are expressed as means \pm S.E.M. ${ }^{*} P<0.05$ between normal and diabetic control and between diabetic control and diabetic fed on treated cells extract.

The islet cells are seen embedded within the acinar cells and surrounded by a fine capsule (Fig. 4).

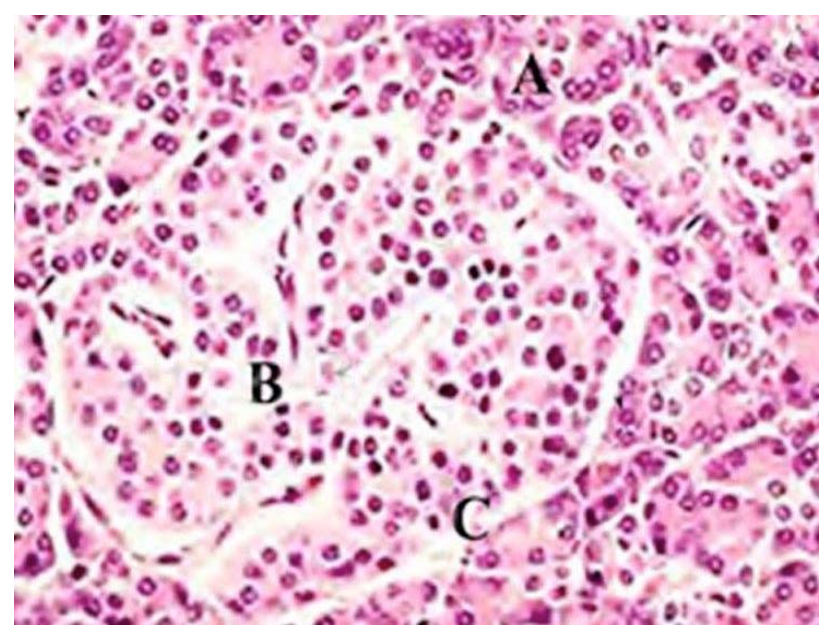

Fig. (4). Light photomicrograph of a section of pancreas of the normal rats. The acinar cells (A) are arranged in lobules with prominent nuclei. The islet cells (B) are seen embedded within the acinar cells and surrounded by a fine capsule (C). H\&E (X 400).

Pancreatic cells of the STZ-diabetic rats (control) showing a progressive distortion in the histoarchitecture of the pancreatic parenchyma and stroma compared to normal group.

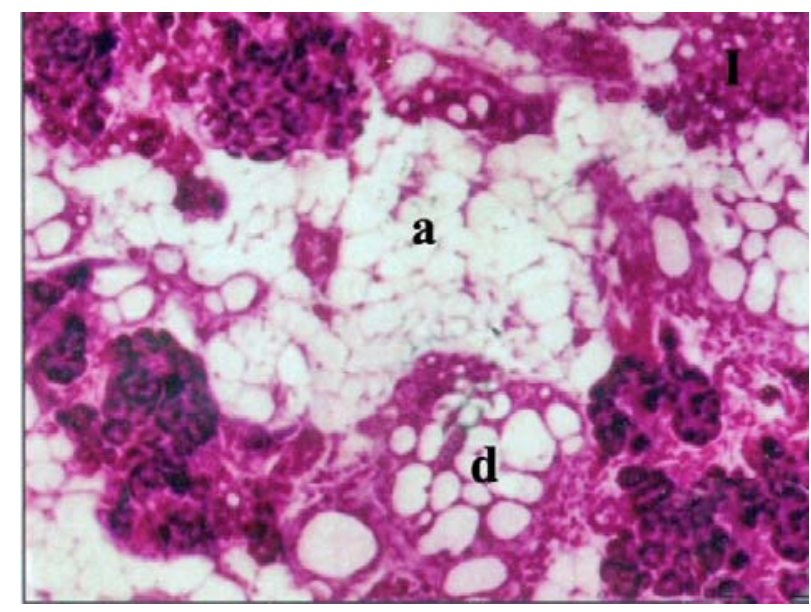

Fig. (5). Light photomicrograph of a section of pancreas of STZdiabetic rats (control) showing massive histological changes; the adipose tissue (a); cystic duclal hyperplasia (d) and adenomatous ductal hyperplasia (I). H\&E (X 400).
A marked increase in the adipose tissue was found at the expense of the functional pancreatic mass, many fragmented islets and areas of progressive interstitial fibrosis (Fig. 5) with a heavy lymphocytic infiltration in and around it with an ill-defined capsule (Fig. 6).

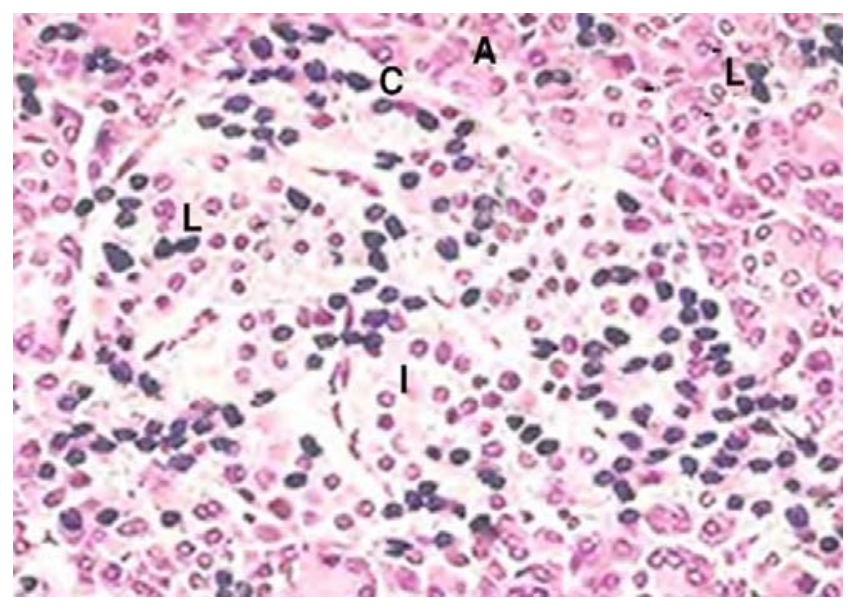

Fig. (6). Light photomicrograph of a section of pancreas of STZdiabetic rats (control) showing the acinar cells (A) were seen to be normal. The islets (I) were present with heavy lymphocytic infiltration in and around it (L) with an ill-defined capsule (C). H\&E (X 400).

The pancreas of STZ-diabetic rats fed with seeds extract showed the acinar cells to be normal. The islets were mildly increased in number with scanty lymphocytic infiltration within the well defined capsule (Fig. 7).

The pancreas of STZ-diabetic rats fed with extract of cells treated with MJ showed normal appearance of acinar cells. The islets are present with a large proportion of islet cells as compared with control. There are few inflammatory cells within the well defined capsule and an increase in the size of blood vessels (Fig. 8).

\section{Ultrastructural Picture}

Transmission electron photomicrograph of pancreas of normal rats showed alpha cells with normal sized cytoplasmic secretory granules. The nuclei are regularly outlined and have two nucleoli (Fig. 9).

Transmission electron photomicrograph of pancreas of STZ-diabetic rats (control) showed the damaged beta cell contains a large vacuole (V) \& amorphous material (M) filling a space formerly occupied by beta granules and the 


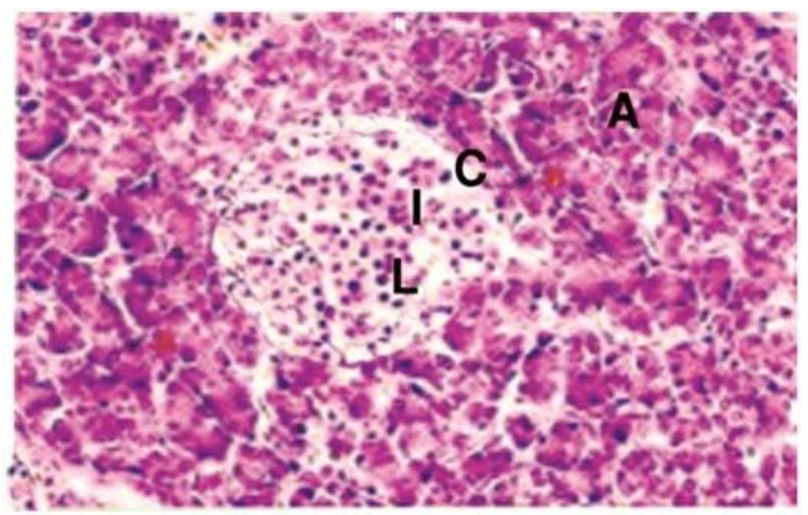

Fig. (7). Light photomicrograph of a section of pancreas of STZdiabetic rats fed with seeds extract showing the acinar cells (A) appeared normal. The islets (I) were mildly increased in number with scanty lymphocytic infiltration (L) and a well defined capsule (C). H\&E (X 400).

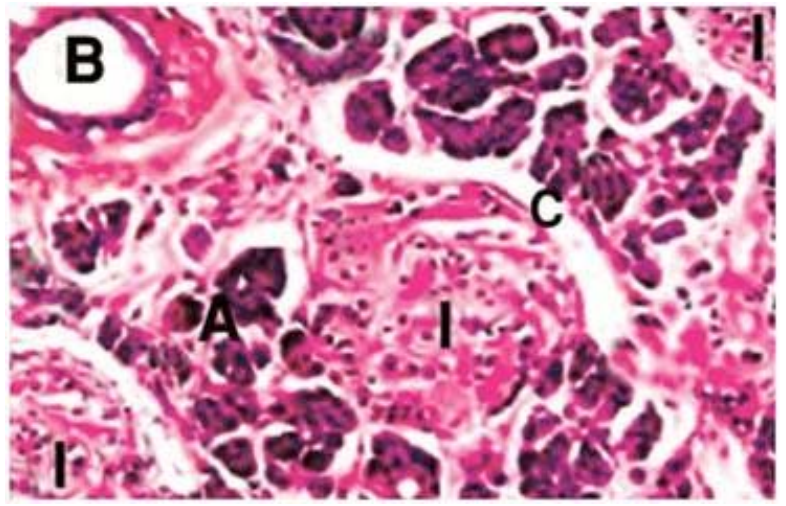

Fig. (8). Light photomicrograph of a section of pancreas of STZdiabetic rats fed with extract of cells treated with MJ showing the acinar cells (A) appeared normal. The islets are present with a large proportion of islet cells with a smaller volume as compared with control. There is very scanty inflammatory cell with well defined capsule (C) and increased in size of blood vessels (B). H\&E (X 400).

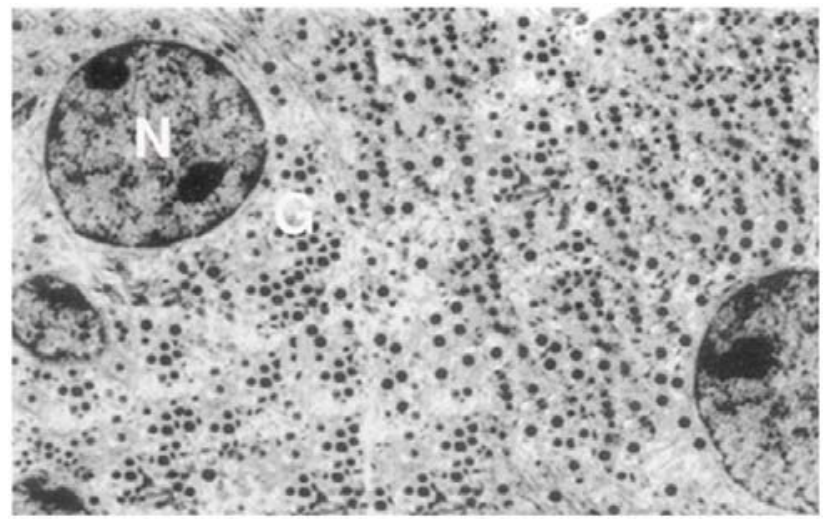

Fig. (9). Transmission electron photomicrograph of pancreas of normal rats showing two adjacent alpha cells showing normal sized cytoplasmic secretory granules $(\mathrm{G})$. The nuclei $(\mathrm{N})$ are regularly outlined and have two nucleoli. (Double fixation \& Double stain. X 10,000).

nucleus $(\mathrm{N})$ is fairly regular in outline with two well defined nucleoli (Fig. 10).

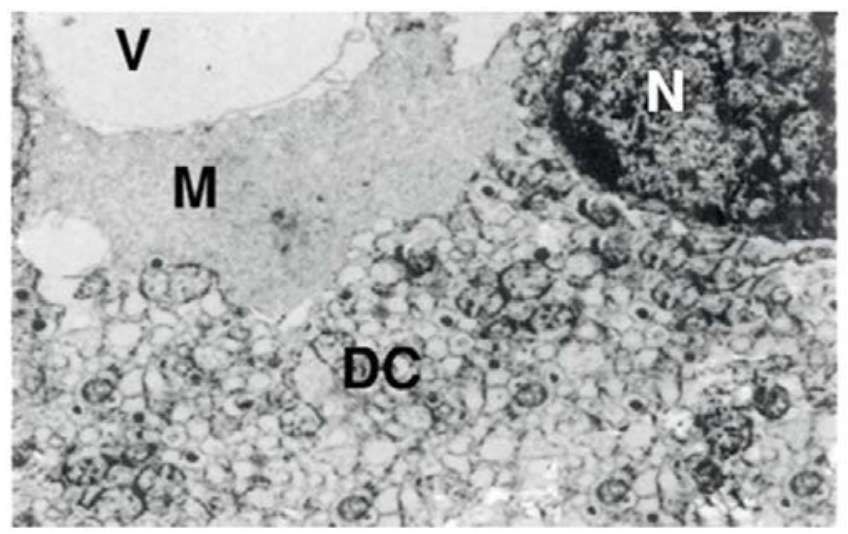

Fig. (10). Transmission electron photomicrograph of pancreas of STZ-diabetic rats (control). The damaged beta cell (DC) contains a large vacuole (V) \& amorphous material (M) filling a space formerly occupied by beta granules. The nucleus $(\mathrm{N})$ is fairly regular in outline with well defined nucleoli. (Double fixation \& Double stain. X 10,000).

Transmission electron photomicrograph of pancreas of STZ-diabetic rats fed with seeds extract showed nearly normal beta cells is less number of vacuoles with swollen mitochondria, the cytoplasmic granules having an electron dense core surrounded by a clear zone and the nucleus is fairly regular in outline with two well defined nucleoli (Fig. 11).

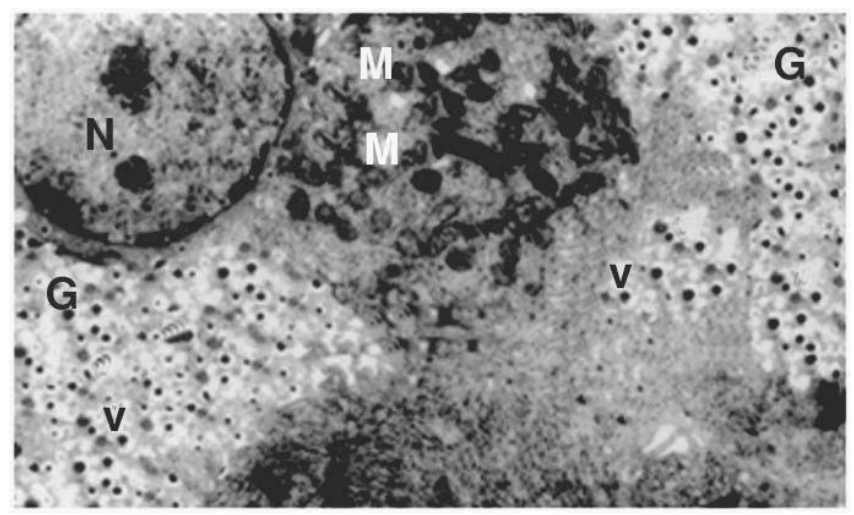

Fig. (11). Transmission electron photomicrograph of pancreas of STZ-diabetic rats fed with seeds extract showing nearly normal beta cells is less number of vacuoles (V) with a swollen mitochondria (M) the cytoplasmic granules (G) having an electron dense core surrounded by a clear zone and the nucleus (N) is fairly regular in outline with two well defined nucleoli. (Double fixation \& Double stain. X 10,000).

Transmission electron photomicrograph of pancreas of STZ-diabetic rats fed with extract of cells treated with MJ showed damaged beta cells is scanty vacuoles with nearly normal mitochondria the cytoplasmic granules having an electron dense core surrounded by a clear zone and the nucleus is nearly regular in outline (Fig. 12).

\section{CONCLUSION}

It is important to conclude the role of plant tissue culture used in this experiment as an alternative source for large scale production of bioactive compounds. Methyl jasmonate 


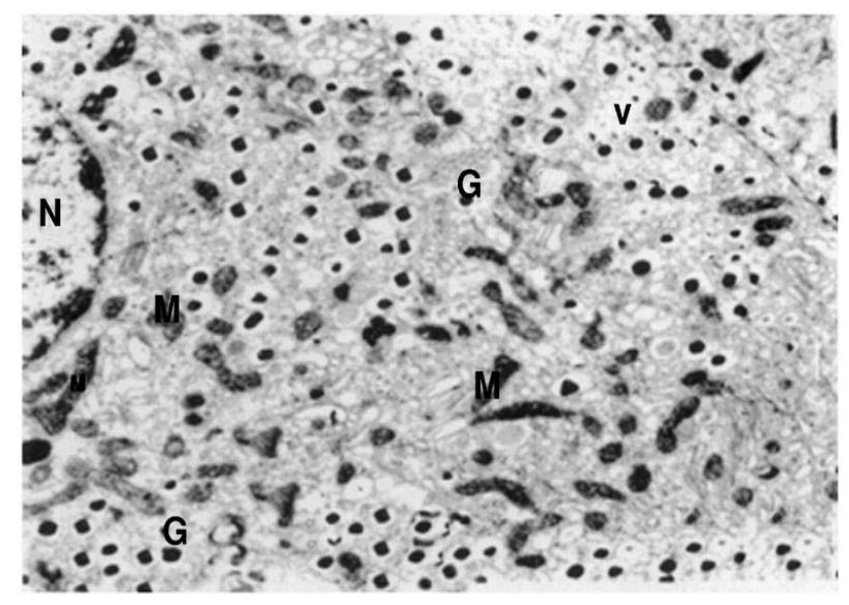

Fig. (12). Transmission electron photomicrograph of pancreas of STZ-diabetic rats fed with extract of cells treated with MJ showing nearly normal beta cells with scanty vacuoles (V) and nearly normal mitochondria (M) the cytoplasmic granules (G) having an electron dense core surrounded by a clear zone and the nucleus $(\mathrm{N})$ is nearly regular in outline. (Double fixation \& Double stain. X 10,000).

(MJ) used in this experiment affected positively the accumulation of both trigonelline and 4-hydroxyisoleucine in cell suspension cultures of Trigonella foenum graecum L. The noticeable improvement in the histology of pancreas of STZ-diabetic rats fed with extract of cells treated with MJ is coincided with significant hypoglycemic activity than that for seeds extract.

\section{REFERENCES}

[1] Morcos, S.R.; Elhawary, Z.; Gabrial, G.N. Protein rich food mixtures for feeding the young in Egypt. 1. Formulation. Z. Ernahrungswiss, 1981, 20, 275-282.

[2] Yoshikawa, M.; Murakami, T.; Komatsu, H.; Murakami, N.; Yamahara, J.; Matsuda, H. Medicinal food stuffs. IV. Fenugreek seed. (1): structures of trigoneosides Ia, Ib, IIa, IIb, IIIa, and IIIb, new furostanol saponins from the seeds of Indian Trigonella foenum graecum L. Chem. Pharm. Bull., (Tokyo), 1997, 45(1), 8187.

[3] Patil, S.P.; Niphadkar, P.V.; Bapat, M.M. Allergy to fenugreek (Trigonella foenum graecum). Ann. Allergy Asthma Immunol., 1997, 78, 297-300.

[4] Kassaian, N.; Azadbakht, L.; Forghani, B.; Amini, M. Effect of fenugreek seeds on blood glucose and lipid profiles in type 2 diabetic patients. Int. J. Vitamin Nutr. Res., 2009, 79(1), 34-9.

[5] Gupta, A.; Gupta, R.; Lal, B. Effect of hydroalcoholic extracts of fenugreek seeds (Trigonella foenum-graecum) on insulin resistance and glycemic control in type 2 diabetes. J. Assoc. Physicians India 2001, 49, 1057-1061.

[6] Sharma, R.D.; Raghuran, T.C. Hypoglycaemic effect of fenugreek seeds in non-insulin depednent diabetic subjects. Nutr. Res., 1990, 10, 731-739.

[7] Sharma, R.D.; Raghuram, T.C.; Rao, N.S. Effect of fenugreek seeds on blood glucose and serum lipids in type 1 diabetes. Eur. $J$. Clin. Nutr., 1990, 44, 301-306.

[8] Neveen, H.Abou El-Soud.; Khalil, M.Y.; Hussein, J.S.; Oraby, F.S.H.; Hussein Farrag, A.R. Antidiabetic effects of Fenugreek alkaloid extract in streptozotocin induced hyperglycemic rats. $J$. Appl. Sci. Res., 2007, 3(10), 1073-1083.

[9] Thakran, S.; Siddiqui, M.R.; Baquer, N.Z. Trigonella foenum graecum seed powder protects against histopathological abnormalities in tissues of diabetic rats. Mol. Cell Biochem., 2004, 266(1-2), 151-9.

[10] Hamden, K.; Jaouadi, B.; Carreau, S.; Aouidet, A.; El-Fazaa, S.; Gharbi, N.; Elfeki, A. Potential protective effect on key steroidogenesis and metabolic enzymes and sperm abnormalities by fenugreek steroids in testis and epididymis of surviving diabetic rats. Arch. Physiol. Biochem., 2010, 116(3), 146-55.

[11] Hamden, K.; Masmoudi, H.; Carreau, S.; Elfeki, A. Immunomodulatory, beta-cell, and neuroprotective actions of fenugreek oil from alloxan-induced diabetes. Immunopharmacol. Immunotoxicol., 2010, 32(3), 437-45.

[12] Jelodar, G.A.; Maleki, M.; Motadayen, M.H., Sirus, S. Effect of fenugreek, onion and garlic on blood glucose and histopathology of pancreas of alloxan induced diabetic rats. Indian J. Med. Sci., 2005, 59(2), 64-9.

[13] Narender, T.; Puri, A.; Shweta; Khaliq, T., Saxena, R.; Bhatia, G.; Chandra, R. 4-Hydroxyisoleucine an unusual amino acid as antidyslipidemic and antihyperglycemic agent. Bioorg. Med. Chem. Lett., 2006, 16(2), 293-6.

[14] Sauvaire, Y.; Petit, P.; Broca, C.; Manteghetti, M.; Baissac, Y.; Fernandez-Alvarez, J.; Gross, R.; Roye, M.; Leconte, A.; Gromis, R.; Ribes, G. 4-Hydroxyisoleucine - a novel amino acid potentiator of insulin secretion. Diabetes 1998, 47, 206-210

[15] Mazza, G.; Oomah, B.D. Chemistry and pharmacology of fenugreek, in Herbs, Botanicals and Teas. Technomic Publishing Co., Lancaster, USA. eds., 2000.

[16] Reinhard, E. Possibilities of using tissue cultures (= cell cultures) in medicinal plant research. Planta Med, 1975, Suppl., 1-4.

[17] Staba, E.J. Plant tissue culture as a source of Biochemicals. CRC press, Boca Raton, Florida, 1980, 59-67

[18] Butenko, R.G. Plant cell culture (Biological series). MIR publisher, MOSCOW, USSR, 1985.

[19] Anderson, L.A.; Phillipson, J.D.; Roberts, M. Biosynthesis of secondary products by cell cultures of higher plants. Adv. Biochem. Eng./Biotechnol. In: Fiechter, A.; Ed. Plant Cell Culture 1985, 31, 1-36.

[20] Abdelmawla, A.M.A. Production of cycloartane triterpene glycosides in shoot cultures of Astragalus sieberi DC. Nat. Product Res., 2010, 24(5), 416-422.

[21] Abdelmawla, A.M.A. Effect of certain elicitors on production of pyrrolizidine alkaloids in hairy root cultures of Echium rauwolfii. Pharmazie 2010, 65, 224-226.

[22] Abdelmawla, A.M.A. Cardiac glycosides from shoot cultures of Cryptostegia grandiflora. Pharmacognosy Res., 2010, 2(1), 15-18.

[23] Murashige, T.; Skoog, F. A revised medium for rapid growth and bioassays with Tobacco tissue culture. Physiol. Plant 1962, 15, 473-497.

[24] El-Shazly, A.; Abdel-All, M.; Tei, A.; Wink, M. Pyrrolizidine alkaloids from Echium rauwolfii and Echium horridum (Boraginaceae). Z. Naturforsch., 1999, 54c, 295-300.

[25] Wagner, H.; Bladt, S. Plants Drug Analysis: A Thin Layer Chromatography Atlas. 2nd. Berlin: Springer, 1996, 306-64.

[26] Singab, A.B.; El-Beshbishy, H.A.; Yonekawa, M.; Nomura, T.; Fukai, T. Hypoglycemic effect of Egyptian Morus alba root bark extract: Effect on diabetes and lipid peroxidation of streptozotocininduced diabetic rats. J. Ethnopharmacol., 2005, 100(3), 333-338.

[27] Bancroft, J.D.; Gamble, M. Theory and practice of histological techniques, $5^{\text {th }}$ ed., Churchill Livingstone. New York, Edinburgh and London, 2002, 126, 173-175.

[28] Trinder, P. Determination of blood glucose using an oxidase peroxidase system with a non-carcinogenic chromogen. J. Clin. Pathol., 1969, 22, 158-161.

[29] Temple, R.C. ; Clarck, P.M. ; Hales, C.N. Measurement of insulin secretion in type 2 diabetes: problems and pitfalls. Diab. Med., 1992, 9, 503-512.

[30] Nair, S.; Nagar, R. Antioxidant flavonoids in common Indian foods. South Asian J. Prev. Cardiol., 1997, 1, 33-35.

[31] Baldwin, I. The jasmonate cascade and complexity of induced defence against herbivore attack. In: Function of Plant Secondary 
Metabolites and their Exploitation in Biotechnology. Annual Plant Reviews, 3, Wink, M., Ed. Sheffield Academic Press, Sheffield, 1999.

[32] Qian, Z.G.; Zhao, Z.J.; Xu, Y.; Qian, X.; Zhong, J.J. Novel chemically synthesized hydroxyl-containing jasmonates as powerful inducing signals for plant secondary metabolism. Biotechnol. Bioeng., 2004, 86(7), 809-16.

[33] Kim, B.J.; Gibson, D.M.; Shuler, M.L. Effect of subculture and elicitation on instability of taxol production in Taxus sp. suspension cultures. Biotechnol. Prog., 2004, 20(6),1666-73.

[34] Cho, H.Y.; Rhee, H.S.; Yoon, S.Y.; Park, J.M. Differential induction of protein expression and benzophenanthridine alkaloid accumulation in Eschscholtzia californica suspension cultures by methyl jasmonate and yeast extract. J. Microbiol. Biotechnol., 2008, 18(2), 255-62.

(C) Abd-El Mawla and Osman; Licensee Bentham Open.

This is an open access article licensed under the terms of the Creative Commons Attribution Non-Commercial License (http://creativecommons.org/licenses/by-nc/3.0/) which permits unrestricted, non-commercial use, distribution and reproduction in any medium, provided the work is properly cited. 